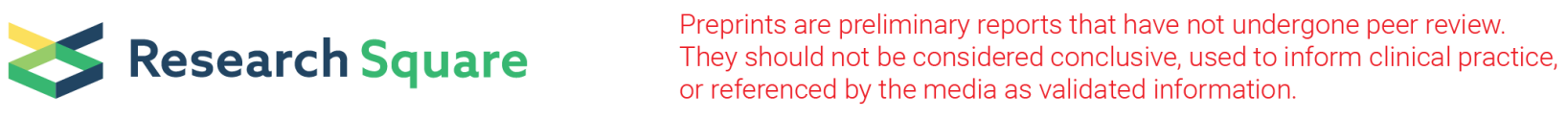

\title{
Improving awareness and help seeking for Obsessive Compulsive Disorder in ethnic minority youth
}

Gazal Jones ( $\sim$ drgazaljones@gmail.com )

Michael Rutter Centre, Maudsley Hospital https://orcid.org/0000-0002-3994-0767

Amita Jassi

Michael Rutter Centre, Maudsley Hospital

Kike Thomas-Smith

Michael Rutter Centre, Maudsley Hospital

\section{Research article}

Keywords: Obsessive Compulsive Disorder, mental health promotion, ethnic minorities, youth, community interventions

Posted Date: June 9th, 2020

DOI: https://doi.org/10.21203/rs.3.rs-32169/v1

License: (c) (i) This work is licensed under a Creative Commons Attribution 4.0 International License. Read Full License 


\section{Abstract}

Background: Inequalities in access, and use of, mental health services by ethnic minorities have been consistently reported for Obsessive Compulsive Disorder (OCD). Mental health promotion may improve knowledge and help seeking. The present study trialled two methods of mental health promotion interventions for ethnic minority youth with OCD.

Methods: Community organisations within an ethnically diverse area of London UK, were contacted; information stalls and teaching events on OCD were delivered as interventions. Participants completed questionnaires before and after the information stalls and teaching events. The questionnaires assessed knowledge of OCD, knowledge of identifying OCD in ethnic minorities and perceived help seeking. Participant questionnaire data collected through information stalls $(\mathrm{N}=240)$ consisted predominantly of youth aged 18 years and under (51.2\%) and of Black (39.0\%) ethnicity. Participant questionnaire data collected at teaching events $(\mathrm{N}=350)$ consisted predominantly of school staff $(51.1 \%)$ where student ethnicity representation within the schools was $29.9 \%$ White, 34\% Black, 13.5\% South East Asian or Asian and $16.6 \%$ Mixed.

Results: There were significant increases in knowledge of OCD, perceived help seeking or knowing how to seek help ratings pre to post information stalls and teaching events. Participants also rated their knowledge of identifying OCD in ethnic minority youth as higher after teaching events.

Conclusions: Information stalls and teaching events may be useful in mental health promotion interventions in ethnic minority youth with $O C D$. Further research is needed to determine whether increase in knowledge and perceived help seeking led to increased referrals to mental health services.

\section{Background}

Inequality in access and use of mental health services by ethnic minorities is well documented [1-5]. This is despite research over the last two decades demonstrating that ethnic minorities have similar if not increased rates of prevalence for a range of mental health conditions when compared to their White counterparts [6-9]. There is a drive both in the UK and US to reduce these inequalities by reducing discrimination in access to service on the grounds of race or ethnicity, and by encouraging services to secure equality of access to treatment across ethnicities [10-13].

Obsessive Compulsive Disorder (OCD) is a debilitating heterogeneous condition [14], with onset in early adolescence and increases in severity if left untreated [15-17]. OCD is equally prevalent across ethnicities [7, 18-19], with ethnic minority groups showing similar gains from evidence-based treatment when compared to their White-counterparts [20]. Despite this, inequalities in access, and use of, mental health services by ethnic minorities have been consistently reported [5, 21-23].

In order to improve access to and use of mental health services as early as possible, it is important to understand the barriers ethnic minorities face when seeking mental health support. Existing literature in 
this area suggests unique barriers for those from ethnic minority backgrounds in accessing rather than receiving support. Studies on OCD report different beliefs about mental health, insufficient mental health literacy, not knowing where to find help, fears of stigma and discrimination, lack of integration with religious and community groups and inaccessibility as barriers to accessing support [24-26]. Some of these barriers are also reported by ethnic minority parents when they were asked about their help-seeking attitudes if their child was struggling with OCD. Fernandez de la Cruz et al. [27] found that parents from ethnic minority backgrounds did not have as much knowledge about OCD and felt treatment would not be helpful when compared to White British parents. These barriers highlight the importance of improving knowledge and understanding of OCD across ethnic minorities and relieving fears of stigma and discrimination through offering support within the community.

Mental health promotion interventions have been employed in various settings and for a range of mental health difficulties to improve knowledge and understanding of mental health conditions and to support positive behavioural change [28-31]. In youth, both community and school based mental health promotion interventions have moderate to strong evidence in improving knowledge and health positive behaviours, with whole school based interventions and community interventions having the strongest effects on knowledge and behavioural change [30-33]. Similar effects for school and community-based mental health interventions have been found in non-Western youth [34-37]. Balaji et al. [36] delivered a community mental health intervention to 1803 youth in India and found significant improvements in knowledge of and attitudes to mental health, reduced reported risk-taking behaviour and higher reported help seeking for sexual health problems compared to waitlist. In a randomised control trial of 664 children and adolescents in Palestine, Khamis et al. [37] found improvements in attributional styles of emotional difficulties, reduced self-blame and improved conduct problems in youth affected by armed conflict compared to waitlist control. These interventions suggest that mental health promotion may alleviate some of the barriers to accessing mental health support such as mental health literacy and help seeking.

Mental health promotion interventions with ethnic minorities in Western countries such as the UK and US may similarly be beneficial in tackling barriers to accessing mental health support. However, research is severely limited in this area, particularly with ethnic minority youth. Knifton et al. [38] trialled mental health promotion interventions with ethnic minorities in the UK in the form of mental health awareness workshops. They measured knowledge and attitudes of mental health and behavioural intent before and after the intervention, all of which significantly improved after the intervention. They found the most commonly reported change in behavioural intent was seeking help for mental health difficulties. Preliminary findings from church-based health promotion studies in the US also indicate some improvement in health positive behaviours for ethnic minorities following intervention [39-40]. This research demonstrates that mental health promotion interventions in the community may be an effective means of addressing barriers to help seeking by improving mental health knowledge and help-seeking in ethnic minorities. Given in OCD, it has been found that parents from ethnic minority backgrounds did not have as much knowledge about OCD or how to seek help for OCD [27] this type of intervention may be worthy of exploration. 
To our knowledge, several guidelines exist on implementing mental health promotion interventions with ethnic minorities [e.g., 41-42]. However, there has been no previous research evaluating mental health promotion interventions in ethnic minority youth with OCD. This study aimed to address this gap by delivering mental health promotion interventions for OCD within an ethnically diverse area of South London, UK and assessing whether these interventions led to improved knowledge of OCD symptoms and treatment, and perceived ability to seek help. The present study trialled two methods of interventions for youth: information stalls and teaching events across a range of community settings, including schools.

\section{Methods}

\section{Participants}

Participants were recruited from four ethnically diverse London boroughs, Southwark, Lewisham, Lambeth and Croydon, which constitute the catchment area of the South London and Maudsley National Health Service Foundation Trust, UK. The most recent census for this catchment area by the Office for National Statistics [43] estimated proportions of ethnic populations: $81.7 \%$ White, $10 \%$ Black, $4.4 \%$ South East Asian or Asian, 2.8\% Mixed and 1\% other. Employment data indicated that of the population aged 16 and above within the catchment area $88.1 \%$ are in employment, $4.1 \%$ students and $7.8 \%$ unemployed [43]. Of those unemployed $42.5 \%$ were White and $38.2 \%$ were from Black/African/Caribbean/Black British backgrounds.

\section{Procedure}

It is well acknowledged that community participation in the design and delivery of community interventions improve the effectiveness of community interventions [44]. We therefore worked in partnership with service users, experts by experience and staff in the community when developing materials for the intervention and delivering the interventions. These materials included an information leaflet on $O C D$, a signs and symptoms card, a leaflet describing the OCD treatment pathway, and a video [45] on service users and parents describing their experience of OCD and treatment.

Content of teaching was established following a focus group with six teachers and six young people separately at two different secondary schools within the catchment area. Feedback in focus groups was used to design presentation slides and slides included: description of OCD symptoms, a video on OCD [45], prevalence, evidence-based treatment, how to identify OCD within school settings, strategies for supporting students and how to share concerns with parents.

Information stalls and teaching workshops were then offered to a range of organisations (e.g., youth centres, libraries, religious centres, schools) in the catchment area, via email, telephone calls, and visits. Information stalls and teaching events were set up in organisations that expressed an interest. We contacted 135 organisations and of these, 37 (27.4\%) expressed an interest. Religious centres had the lowest uptake with three (9\%) of 28 contacted expressing an interest and only one where a stall was set up. Teaching events were held at secondary schools, high schools and youth centres. Participants were 
recruited over an eight-month period and consented to completing questionnaires before discussions at the information stall or before teaching events.

Information stalls Information stalls were set up in various locations with the resources above on display. People approaching the stall had the opportunity to have face-to-face discussions on OCD with a Clinical Psychologist or Assistant Psychologist of South East Asian and Mixed ethnicity, respectively. In these discussions, clinicians explained key facts about OCD in relation to symptomatology, prevalence and treatment. Participants also watched an animated video on OCD [46].

Teaching events A Clinical Psychologist, Assistant Psychologist and a young person with lived experience of OCD delivered the teaching and events ranged from 45 minutes to 75 minutes.

Measures Two questionnaires were developed by a Consultant Clinical Psychologist and Clinical Psychologist for information stalls and teaching events. Participants completed the questionnaire before and after visiting the information stall or attending the teaching event. Please see supplementary information for copies of the original questionnaires.

Information stalls The questionnaire required participants to give ratings for knowledge of OCD and likelihood of seeking help or supporting someone in seeking help when they first approached the stall and after they had had a chance to look and discuss the information in the stall. The questionnaire included four items ( 2 items completed pre-information stall and 2 items post information stall). Responses were measured on a Likert scale e.g., 1 = strongly disagree to $5=$ strongly agree. Examples of items included: 'Do you know how someone could get help for OCD?'

Teaching events The questionnaire required participants to give ratings for knowledge of OCDknowing how to support someone in seeking help and knowledge in recognising ethnic minority youth with OCD before and after the teaching event. included 6 items ( 3 items completed pre-teaching and 3 items completed post teaching). Responses were measured on a Likert scale range from $1=$ very low to $10=$ very high. Examples of items included: 'How would you rate your knowledge of recognising OCD in the Black Asian and Minority Ethnic (BAME) population?' and 'How would you rate your skills in helping children and young people with OCD?' Both questionnaires also had two or three open-ended questions respectively for generic feedback.

\section{Statistical analysis}

Normality of data was tested using Shapiro-Wilk test which indicated that all but one (pre-information stall help-seeking ratings, $p=.609$ ) questionnaire item data was not normally distributed (remaining items, $p=.000$-.008). Non-parametric Wilcoxon signed-rank tests were therefore used to compare pre and post differences in median questionnaire ratings for each item. Bonferroni corrections were applied due to multiple comparisons. Two tests were corrected for in information stalls data and three tests were corrected for in teaching event data. 


\section{Results}

\section{Information stalls}

A total of 16 information stalls were set up and 240 participants visited the information stalls.

Information stalls at independent youth events had the most number of contact ( $33 \%, N=79$ ), followed by schools $(27 \%, N=64)$, libraries $(26 \%, N=63)$, General Practitioner clinics $(9 \%, N=21)$ and religious centres $(5 \%, N=13)$. Participants included $51.2 \%(\mathrm{~N}=123)$ people aged 18 years and under and $14.6 \%(\mathrm{~N}=35)$ adults aged 19 and above $34.1 \%(\mathrm{~N}=82)$ of participants did not give this information). Participants consisted of 9.8\% ( $\mathrm{N}=24)$ White, 39.0\% ( $=93)$ Black, 4.9\% ( $=12)$ South East Asian or Asian, 4.9\% ( $=12)$ Mixed and $7.3 \%(\mathrm{~N}=17)$ other $(34.1 \%, \mathrm{~N}=82$ of participants did not give this information).

The Wilcoxon signed-ranks tests were carried out to test for change in knowledge and help seeking ratings pre- and post-information stalls. As shown in figure 1, the tests indicated that there was an increase in knowledge of OCD following a visit to the information stalls $(Z=-.231, p=.042)$ with the median score increasing from 4.0 to 5.0. The visit to the information stall also increased help seeking/knowing how to seek help ratings $(Z=-2.26, p=.048)$ with the median score increasing from 3.0 to 4.0 .

\section{Teaching events}

350 participants attended the teaching events, of which the majority were school staff $(51.1 \%, N=179)$, followed by youth workers $(4.8 \%, N=17)$, Mental Health Professionals $(15.1 \%, N=53)$, Primary Health Care Professionals $(8.7 \%, \mathrm{~N}=30)$ and other staff $(1 \%, \mathrm{~N}=3)(19.3 \%, \mathrm{~N}=68$ of attendees did not give this information). Participants included $7.4 \%(\mathrm{~N}=26)$ young people aged 18 years and under and $71.7 \%(\mathrm{~N}=$ 251 ) adults aged 19 and above (20.9\%, $N=73$ of participants did not give this information). Student ethnicity representation within the schools where we conducted teaching events was $34 \%$ Black, $29.9 \%$ White, $16.6 \%$ Mixed, $13.5 \%$ South East Asian or Asian, and $6.1 \%$ other [47].

Wilcoxon signed-ranks tests were carried out to test for change in knowledge of OCD, skills in helping youth with OCD and knowledge in identifying OCD in ethnic minority youth pre and post-teaching events. The tests indicated that there was an increase in knowledge of OCD following the teaching events $(Z=$ $-13.25, p<.001$ ) with the median score increasing from 4.0 to 7.0 . As shown in figure 1 , the teaching events also increased knowledge in identifying OCD in ethnic minority youth $(Z=-12.63, p<.001)$ with the median score increasing from 3.0 to 7.0 and skills in helping youth with $\operatorname{OCD}(Z=-12.36, p<.001)$ with the median score increasing from 4.0 to 7.0 .

\section{Conclusions}

The present study trialled two methods of mental health promotion - information stalls and teaching events and assessed if they improve knowledge of OCD symptoms and treatment and perceived ability to seek help. To our knowledge, this study is the first to implement and evaluate mental health promotion interventions in ethnic minority youth with OCD. 
The results suggest that both information stalls and teaching events increased knowledge of OCD and perceived help seeking or knowing how to seek help. Teaching events also led to increased knowledge in identifying OCD in ethnic minority youth amongst school staff, youth workers, mental health professionals working with ethnic minority youth, as well as ethnic minority youth. These findings support previous studies reporting increased knowledge and understanding of mental health and helpseeking following health promotion interventions [38]. The findings also suggest that these interventions may be useful method of addressing barriers reported by ethnic minorities in accessing mental health support on having insufficient mental health literacy and not knowing where to find help [27].

We could not statistically compare ratings across information stalls and teaching events due to the nature of the data. However, ratings were higher for knowledge of OCD, perceived help seeking and how to seek help for teaching events than for information stalls. The higher ratings may have been due to the difference in length, content and quality of the interventions. Information stalls provided shorter one-toone conversations of up to 20 minutes whereas teaching events included presentations up to 75 minutes. The content covered within teaching events was therefore likely to be more comprehensive. However, it could be argued that one-to-one conversations may have been of better quality rather than the large teaching events as participants had a chance to ask questions relevant to them in a confidential manner. Information stalls were also accessed directly by young people whereas teaching events were focussed on staff supporting young people.

The mental health promotion interventions also addressed barriers of inaccessibility and lack of integration with community groups. This was done by setting up stalls and teaching in local areas commonly accessed by ethnic minorities and through working closely with staff at the organisations in delivering the interventions. The results suggest that majority of participants accessing the information stalls were of Black ethnicity followed by White, Other, South East Asian or Asian, and Mixed. Interestingly, these figures are over-representative of ethnic minorities when compared to the under 18 ethnicity population figures in the catchment area where White is majority, followed by Black and South East Asian or Asian, Mixed and other [43]. This may have been due to researchers actively approaching ethnic minorities around information stalls. Nonetheless, this overrepresentation is interesting and may suggest that information stalls are a potential method of giving information about mental health to ethnic minority youth.

Teaching events were largely focussed on staff members, which may not be representative of the ethnicity population of the catchment area. Research suggests that professionals' lack of knowledge of OCD and the support available act as additional barriers to seeking support [48-50]. Our interventions with staff are therefore likely to have a knock-on effect for ethnic minorities, for example within schools where a large proportion of the students are of ethnic minority backgrounds. One method of assessing this might be having follow-up with staff working with ethnic minority youth.

The findings of this study need to be considered in light of limitations. The present investigation used self-report measures to assess for change in knowledge and help seeking and findings suggest this may 
be a useful and efficient method of evaluating mental health promotion interventions. There are however no widely accepted and validated self-report measures used for health promotion interventions [51]. Selfreport measures rely on introspective insight and assume participants will behave as they report [52]. Ratings may have however been influenced by response bias where participants give socially acceptable answers despite being reminded of confidentiality, particularly for information stalls where participants had direct contact with researchers [52]. Incorporating an objective evaluative measure to assess for change in knowledge and help-seeking would have further strengthened findings as we cannot conclude actual increase in knowledge and help-seeking from self-report measures. For instance, Jassi et al. [53] assessed factual knowledge about OCD pre and post teachers reading an OCD information pack and found significant increases in knowledge after participants read the information pack. Future research would benefit from assessing increase in knowledge through brief tests of factual knowledge and increase in help seeking through recording actual referrals to mental health services for ethnic minority youth before and after the interventions. There is also a need to validate self-report measures used within health promotion interventions research.

The mental health promotion interventions were offered to religious centres but only one intervention was delivered. There were several challenges to implementation; it was difficult to access contact details for local religious centres and approach them at right times due to variability in services during the week or time of day (e.g., mosques being open during prayer time only). We attempted to approach religious centres in person to overcome these challenges and they were often cautious of the support being offered. However, research suggests that ethnic minorities often seek treatment from religious and traditional healers as this is perceived as less stigmatizing, and thus collaborating with religious leaders may be necessary to increase acceptability of mental health interventions $[26,54]$. For instance, churchbased health promotion where religious leaders were consulted has been found to improve some health positive behaviours [39-40]. Campbell et al. [55] also highlighted the importance of ongoing collaboration and meeting longer-term community needs when offering interventions within religious communities. We learnt that working with religious communities would require continuous linking with key religious leaders, and collaborative reviewing of material used in interventions. There were also some barriers in setting up teaching events in religious centres due to the project specifically being focussed on OCD. It is possible that religious communities may be more open to mental health teaching where broader concerns are considered under the heading of emotional well-being.

Finally, our findings are also limited in generalisability. The health promotion interventions were provided to those who expressed an interest within a limited time frame and not all local organisations were contacted due to the scope of this project. Contacting all local organisations to provide equal opportunity is important and should be considered in future research. We also cannot conclude from the findings of this study that the health promotion interventions delivered are applicable to other mental health conditions such as depression or psychosis. It may be the case that due to the nature of OCD, discussions around this topic were viewed to be more or less acceptable than other mental health conditions. 
The present study is the first to trial health promotion interventions to improve knowledge of and help seeking for OCD specifically targeting ethnic minority youth. The findings suggest that health promotion interventions in the form of community stalls and teaching events improve knowledge of and perceived ability to seek help and know how to seek help for OCD. These results are promising as they suggest that some of the barriers in accessing mental health support can be overcome through health promotion interventions.

\section{Abbreviations}

OCD - Obsessive Compulsive Disorder

UK - United Kingdom

US - United States of America

BAME - Black Asian Minority Ethnic

\section{Declarations}

\section{Ethics approval and consent to participate}

The UK Health Research Authority Research Ethics Committee tool was consulted prior to initiating this project. We were advised that due to the nature of the study, ethics approval was not required.

Participants consented to partake in the present study by agreeing to complete questionnaires provided.

\section{Consent for publication}

Not applicable.

\section{Availability of data and materials}

The datasets used and/or analysed during the current study are available from the corresponding author on reasonable request.

\section{Competing interests}

The authors declare that they have no competing interests.

\section{Funding}

The present investigation was funded by Maudsley Charity, United Kingdom (grant reference number 1114). The funding supported the design of the study as well as data collection and analysis.

\section{Authors' contributions}

GJ contributed to the design of the study, collection of data, analyses, interpretation of results and was a major contributor in writing the manuscript; KTS contributed to data collection, data analysis, interpretation of results and drafted the methods; AJ designed and secured funding for the study, 
oversaw and contributed to data collection, analysis and write up of the manuscript. All authors read and approved the final manuscript.

\section{Acknowledgements}

We would like to thank the Maudsley Charity and the volunteers with lived experience of OCD for giving their time to co-deliver teaching sessions on OCD.

\section{References}

1. Goodman A, Patel V, Leon DA. Child mental health differences amongst ethnic groups in Britain: a systematic review. BMC Public Health. 2008;8(1):258.

2. Cooper C, Tandy AR, Balamurali TB, Livingston G. A systematic review and meta-analysis of ethnic differences in use of dementia treatment, care, and research. Am J Geriatr Psychiatry. 2010;18(3):193-203.

3. Cooper C, Spiers N, Livingston G, Jenkins R, Meltzer H, Brugha T, McManus S, Weich S, Bebbington P. Ethnic inequalities in the use of health services for common mental disorders in England. Soc Psychiatry Psychiatr Epidemiol. 2013;48(5):685-92.

4. Dinwiddie GY, Gaskin DJ, Chan KS, Norrington J, McCleary R. Residential segregation, geographic proximity and type of services used: evidence for racial/ethnic disparities in mental health. Soc Sci Med. 2013;80(1):67-75.

5. Fernandez de la Cruz L, Llorens M, Jassi A, Krebs G, Vidal-Ribas P, Radua J, Hatch SL, Bhugra D, Heyman I, Clark B, Mataix-Cols D. Ethnic inequalities in the use of secondary and tertiary mental health services among patients with obsessive-compulsive disorder. The $\mathrm{Br} \mathrm{J}$ Psychiatry. 2015;207(6):530-5.

6. King M, Coker E, Leavey G, Hoare A, Johnson-Sabine E. Incidence of psychotic illness in London: comparison of ethnic groups. BMJ. 1994;309(6962):1115-9.

7. Weich S, Nazroo J, Sproston K, McManus S, Blanchard M, Erens B, Karlsen S, King M, Lloyd K, Stansfeld S, Tyrer P. Common mental disorders and ethnicity in England: the EMPIRIC study. Psychol Med. 2004;34(8):1543-51.

8. Marques L, Alegria M, Becker AE, Chen CN, Fang A, Chosak A, Diniz JB. Comparative prevalence, correlates of impairment, and service utilization for eating disorders across US ethnic groups: Implications for reducing ethnic disparities in health care access for eating disorders. Int $\mathrm{J}$ Eat Disord. 2011;44(5):412-20.

9. Merikangas KR, He JP, Burstein M, Swanson SA, Avenevoli S, Cui L, Benjet C, Georgiades K, Swendsen J. Lifetime prevalence of mental disorders in US adolescents: results from the National Comorbidity Survey Replication-Adolescent Supplement (NCS-A). J Am Acad Child Adolesc Psychiatry. 2010;49(10):980-9.

10. British Equality Act. http://www.legislation.gov.uk/ukpga/2010/15/contents. 2010. Accessed 30 December 2019. 
11. UK National Institute of Health and Care Excellence 2016-2020. 2016.

https://www.nice.org.uk/Media/Default/About/Who-we-are/Policies-and-procedures/NICE-equalityscheme/equality-objectives-and-equality-programme-16.pdf. Accessed 30 Dec 2019.

12. Substance Abuse and Mental Health Services Administration. National Survey on Drug Use and Health. 2016. https://www.samhsa.gov/data/sites/default/files/NSDUH-DetTabs-2015/NSDUHDetTabs-2015/NSDUH-DetTabs-2015.pdf. Accessed 13 Jan 2020.

13. Roberts LW, Dyer AR. Concise guide to ethics in mental health care. Washington: American Psychiatric Publishing; 2004.

14. Lochner C, Stein DJ. Heterogeneity of obsessive-compulsive disorder: a literature review. Harv Rev Psychiatry. 2003;11(3):113-32.

15. Wewetzer C, Jans T, Müller B, Neudörfl A, Bücherl U, Remschmidt H, Warnke A, Herpertz-Dahlmann B. Long-term outcome and prognosis of obsessive-compulsive disorder with onset in childhood or adolescence. Eur Child Adolesc Psychiatry. 2001;10(1):37-46.

16. Karno M, Golding JM. Obsessive compulsive disorder. In: Tovins LN, Refier DA, editors. Pediatric disorders in America. New York: Free Press; 1991. pp. 204-19.

17. Koran LM, Thienemann ML, Davenport R. Quality of life for patients with obsessive-compulsive disorder. Am J Psychiatry. 1996;153:497-504.

18. Sasson Y, Zohar J, Chopra M, Lustig M, lancu I, Hendler T. Epidemiology of obsessive-compulsive disorder: A world view. J Clin Psychiatry. 1997;58(12):7-10.

19. Sproston K, Nazroo J. Ethnic Minority Psychiatric Illness Rates in the Community (EMPIRIC). London: The Stationery Office; 2002.

20. Fernandez de la Cruz L, Jassi A, Krebs G, Clark B, Mataix-Cols D. Phenomenology and treatment outcomes in children and adolescents from ethnic minorities with obsessive-compulsive disorder. $\mathrm{J}$ Obsessive Compuls Relat Disord. 2015;4:30-6.

21. Himle JA, Muroff JR, Taylor RJ, Baser RE, Abelson JM, Hanna GL, Abelson JL, Jackson JS. Obsessive-compulsive disorder among African Americans and Blacks of Caribbean descent: Results from the national survey of American life. Depress Anxiety. 2008;25(12):993-1005.

22. Ruscio AM, Stein DJ, Chiu WT, Kessler RC. The epidemiology of obsessive-compulsive disorder in the National Comorbidity Survey Replication. Mol Psychiatry. 2010;15(1):53-63.

23. Williams MT, Jahn ME. Obsessive-compulsive disorder in African American children and adolescents: Risks, resiliency, and barriers to treatment. Am J Orthopsychiatry. 2017;87(3):291.

24. Coles ME, Heimberg RG, Weiss BD. The public's knowledge and beliefs about obsessive compulsive disorder. Depress Anxiety. 2013;30(8):778-85.

25. Williams MT, Domanico J, Marques L, Leblanc NJ, Turkheimer E. Barriers to treatment among African Americans with obsessive-compulsive disorder. J Anxiety Disord. 2012;26(4):555-63.

26. Kolvenbach S, Fernández de la Cruz L, Mataix-Cols D, Patel N, Jassi A. Perceived treatment barriers and experiences in the use of services for obsessive-compulsive disorder across different ethnic 
groups: a thematic analysis. Child Adolesc Ment Health. 2018;23(2):99-106.

27. Fernandez de la Cruz L, Kolvenbach S, Vidal-Ribas P, Jassi A, Llorens M, Patel N, Weinman J, Hatch SL, Bhugra D, Mataix-Cols D. Illness perception, help-seeking attitudes, and knowledge related to obsessive-compulsive disorder across different ethnic groups: a community survey. Soc Psychiatry Psychiatr Epidemiol. 2016;51(3):455-64.

28. Durlak JA, Wells AM. Primary prevention mental health programs for children and adolescents: A meta-analytic review. Am J Community Psychol. 1997;25(2):115-52.

29. Jané-Llopis E, Barry M, Hosman C, Patel V. Mental health promotion works: a review. Promot Educ. 2005;12(2):9-25.

30. Weare K, Nind M. Mental health promotion and problem prevention in schools: what does the evidence say? Health Promot Int. 2011;26(1):29-69.

31. Barry MM, Clarke AM, Jenkins R, Patel V. A systematic review of the effectiveness of mental health promotion interventions for young people in low and middle income countries. BMC Public Health. 2013;13(1):835.

32. Wells J, Barlow J, Stewart-Brown S. A systematic review of universal approaches to mental health promotion in schools. Health Educ. 2003;103(4):197-220.

33. Tennant R, Goens C, Barlow J, Day C, Stewart-Brown S. A systematic review of reviews of interventions to promote mental health and prevent mental health problems in children and young people. J Public Ment Health. 2007;6(1):25.

34. Rivet-Duval E, Heriot S, Hunt C. Preventing adolescent depression in Mauritius: A universal schoolbased program. Child Adolesc Ment Health. 2011;16(2):86-91.

35. Rahman A, Mubbashar MH, Gater R, Goldberg D. Randomised trial of impact of school mental-health programme in rural Rawalpindi, Pakistan. The Lancet. 1998;352(9133):1022-5.

36. Balaji M, Andrews T, Andrew G, Patel V. The acceptability, feasibility, and effectiveness of a population-based intervention to promote youth health: an exploratory study in Goa, India. J Adolesc Health. 2011;48(5):453-60.

37. Khamis V, Macy R, Coignez V. The impact of the classroom/community/camp-based intervention (CBI) program on Palestinian children. USA: Save the Children; 2004.

38. Knifton L, Gervais M, Newbigging K, Mirza N, Quinn N, Wilson N, Hunkins-Hutchison E. Community conversation: addressing mental health stigma with ethnic minority communities. Soc Psychiatry Psychiatr Epidemiol. 2010;45(4):497-504.

39. Winett RA, Anderson ES, Wojcik JR, Winett SG, Bowden T. Guide to health: nutrition and physical activity outcomes of a group-randomized trial of an Internet-based intervention in churches. Ann Behav Med. 2007;33(3):251-61.

40. Sauaia A, Welsh AL, Byers T, Min SJ, Jacobellis J. The Effect of Two Church-based Interventions on Breast Cancer Screening Rates Among Medicaid-Insured Latinas. Prev Chronic Dis. 2005;2(4):A07. 
41. Gallagher-Thompson D, Haley W, Guy D, Rupert M, Argüelles T, Zeiss LM, Long C, Tennstedt S, Ory M. Tailoring psychological interventions for ethnically diverse dementia caregivers. Clin Psychol. 2003;10(4):423-38.

42. Bernal G, Sáez-Santiago E. Culturally centered psychosocial interventions. J Community Psychol. 2006;34(2):121-32.

43. Office for National Statistics. Census: Digitised Boundary Data (England and Wales). UK Data Service Census Support. 2011. https://borders.ukdataservice.ac.uk/. Accessed 30 Sept 2019.

44. Wallerstein N, Duran B. Community-based participatory research contributions to intervention research: the intersection of science and practice to improve health equity. Am J Public Health. 2010;100(1):40-6.

45. OCD is not me. Youtube. Stuart White. OCD Action and South London and Maudsley NHS Trust. 2019. . Accessed 29th March 2020.

46. Over and Over (and Over) again. Vimeo. Andy Glynne. South London and Maudsley NHS Trust. 2010. http://cargocollective.com/salvadormaldonado/Over-and-over-and-over-again. Accessed 29th March 2020.

47.

48. Department of Education

Schools, pupils and their characteristics: January 2019 Database Accessed 29th March 2020.

49. Department of Education. Schools, pupils and their characteristics: January 2019 Database. https://www.gov.uk/government/statistics/schools-pupils-and-their-characteristics-january-2019. Accessed 29th March 2020.

50. Stengler-Wenzke K, Angermeyer MC. Employment of professional help by patients with obsessivecompulsive disorders. Psychiatr Prax. 2005;32(4):195-201.

51. Goodwin R, Koenen KC, Hellman F, Guardino M, Struening E. Helpseeking and access to mental health treatment for obsessive-compulsive disorder. Acta Psychiatr Scand. 2002;106(2):143-9.

52. Beşiroğlu L, Çilli AS, Aşk R. The predictors of health care seeking behavior in obsessive-compulsive disorder. Compr Psychiatry. 2004;45(2):99-108.

53. Lister-Sharp D, Chapman S, Stewart-Brown S, Sowden A. Health promoting schools and health promotion in schools: two systematic reviews. In: Database of Abstracts of Reviews of Effects (DARE): Quality-assessed Reviews. York: Centre for Reviews and Dissemination; 1999.

54. Paulhus DP. Measurement and control of response bias. In: Robinson JP, Shaver PR, Wrightsman LS, editors. Measures of personality and social psychological attitudes. San Diego: Academic Press; 1991. pp. 17-59.

55. Jassi AD, Kolvenbach S, Heyman I, Macleod T, Rose J, Diamond H. Increasing knowledge about obsessive compulsive disorder and support for parents and schools: Evaluation of initiatives. Health Educ J. 2016;75(5):600-9. 
56. Wahass S, Kent G. Coping with auditory hallucinations: A cross-cultural comparison between Western (British) and non-Western (Saudi Arabian) patients. J Nerv Ment Dis. 1997;185(11):664-8.

57. Campbell MK, Hudson MA, Resnicow K, Blakeney N, Paxton A, Baskin M. Church-based health promotion interventions: evidence and lessons learned. Annu Rev Public Health. 2007;28:213-34.

\section{Figures}

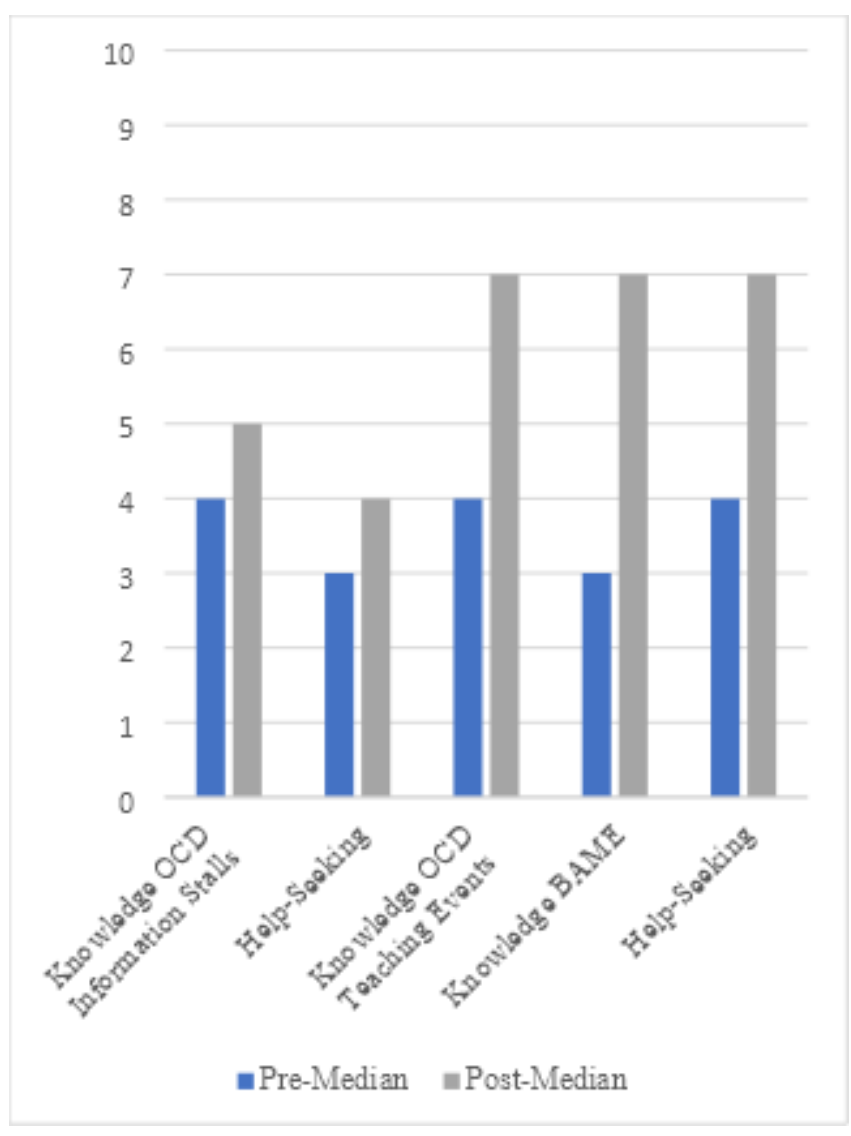

\section{Figure 1}

Pre and post-median ratings on knowledge of OCD, knowledge about identifying OCD in Black Asian Minority Ethnic (BAME) youth and perceived help-seeking for information stalls and teaching events

\section{Supplementary Files}

This is a list of supplementary files associated with this preprint. Click to download.

- supplement5.docx 